\title{
The Comparison between Laparoscopic vs. Open Surgery for Trinitrobenzene Sulfonic Acid-Induced Rat Colitis
}

Oguzhan Karatepe ${ }^{1 *}$, Suleyman Kokdas ${ }^{2}$, Sedat Kamali ${ }^{1}$, Timucin Aydın $^{3}$, Ahu Kemik ${ }^{2}$, Gulcin Kamali ${ }^{1}$, Gokhan Adas ${ }^{2}$ and Enis Yuney ${ }^{3}$ 1Department of Surgery, Okmeydani Training Hospital, Okmeydani/Sisli/lstanbul, Turkey

2Department of Biochemistry, Istanbul Faculty of Medicine, Okmeydani/Sisli/lstanbul, Turkey

3Department of Pathology, Okmeydani Training Hospital, Okmeydani/Sisli/lstanbul, Turkey

\begin{abstract}
Introduction: The etipathogenesis of inflammatory bowel disease (IBD) includes immunologic, genetic and environmental factors. In addition to the colon, frequent extra-intestinal alterations related to pancreas and hepatobiliary system are evaluated in several studies. A minimally invasive approach was applied to the IBD, with the expectation of earlier recovery, fewer postoperative complications.. The aim of the study is to compare the effects of laparoscopic and open techniques applied for the surgical treatment of ulcerative colitis on the gastrointestinal system and pancreas, and related systemic consequences.
\end{abstract}

Methods: Colitis was induced in 20 rats by rectal injection of a $5 \% 0.25 \mathrm{~mL} 10 \mathrm{mg} / \mathrm{kg}$ TNBS (Sigma, USA) in $50 \%$ ethanol. The rats were randomly divided into two groups: rat control, laparotomy was made for two-hour duration $(n=10)$, a pneumoperitoneum was applied for a two-hour duration $(n=10)$. Following the surgical procedures, samples were drawn for biochemical and histopathologic examinations. TNF- $\alpha$, IL-6, MDA, NO, MPO and PAP levels were evaluated in serum and in tissues of pancreas and colon.

Results: Except the MDA and NO levels in colonic tissues, all the parameters indicating the oxidative injury and inflammation were found significantly lower in a pneumoperitoneum group. There was no difference in histopathologic examinations of the both groups.

Discussion: The results revealed that despite the pathophysiologic effects of pneumoperitoneum laparoscopic surgery in patients with ulcerative colitis elicited less oxidative damage and inflammation compared to conventional surgery. Regarding the findings we concluded that laparoscopic procedures are safe in patients with IBD but to comment on the effects of pneumoperitoneum related to the longer surgery duration further studies with variable operation times are required.

Keywords: Inflammatory bowel disease; Oxidative damages; Pancreatitis

\section{Introduction}

Inflammatory bowel disease (IBD) is a chronic progressive disorder of the gastrointestinal system without a fully established aetiology. It includes the ulcerative colitis (UC) and crohn's disease (CD). Both disorders lead to the inflammation in digestive system and result in tissue damage which is not limited to the gastrointestinal system but the damage may also occur enxtraintestinally in variable levels, especially in the hepatobiliary system and pancreas.

Although the treatment of IBD is mostly medical, in the case of unresponsiveness or development of several associated complications, surgery may become inevitable. The surgery may be performed in conventional or laparoscopic techniques; the latter has more supporters lately $[1,2]$. Development of laparoscopic technique and experience makes it possible to succeed in the surgical treatment of ulcerative colitis [3]. Lesser postoperative pain, earlier recovery of gastrointestinal functions, lesser hospital stay with earlier return to the daily activity and together with better cosmetic results, laparoscopic surgery becomes more widely preferred method of surgical treatment.

Despite the favourable outcome and safe performance of laparoscopic surgery for ulcerative colitis the effects of pneumoperitoneum, which is required as the working space, on the colitis itself and on the organs of the patients with colitis are not known.

CO2 is frequently used to develop pneumoperitoneum in laparoscopic surgery. The impacts $\mathrm{CO} 2$ pneumoperitoneum on abdominal organs were found to affect the cardiovascular system, acidbase balance, systemic immune response, hepato-portal perfusion and bacterial translocation. In addition several studies revealed that laparoscopic surgery had no adverse effects on pancreas. But in case of patients with colitis, the effects of laparoscopic intervention on pancreas and on the systemic inflammatory response and on the colitis as well are not well studied.

We aimed to evaluate the impact of laparoscopic surgery on gastrointestinal system and pancreas and the consequent results on the systemic inflammatory system in the treatment of UC.

\section{Materials and Method}

After the development of the study project, an approval from Istanbul University Ethical Council on the Experiments on Animals was obtained. The study was performed in the laboratories of experimental animals of Istanbul University and at least 3 months of age, with an average weight of 200-250g Wistar-Albino female rats were subjected.

*Corresponding author: Oguzhan Karatepe, Department of Surgery, Okmeydan Training Hospital, Okmeydani/Sisli/lstanbul, Turkey, Tel: 34714. 02122217777 E-mail: drkaratepe@yahoo.com

Received November 20, 2010; Accepted December 10, 2010; Published December 20, 2010

Citation: Karatepe O, Kokdas S, Kamali S, Aydın T, Kemik A, et al. (2010) The Comparison between Laparoscopic vs. Open Surgery for Trinitrobenzene Sulfonic Acid-Induced Rat Colitis. J Cytol Histol 1:109. doi:10.4172/2157-7099.1000109

Copyright: (C) 2010 Karatepe O, et al. This is an open-access article distributed under the terms of the Creative Commons Attribution License, which permits unrestricted use, distribution, and reproduction in any medium, provided the original author and source are credited. 
One week before the study, the rats were accommodated in $22 \pm 2 \mathrm{C}$ stable room temperature, the natural day-and-night cycle maintained and they were fed the standard laboratory food while causally assigned to cages so that each cage had 5 rats. They were randomized to 2 groups, each containing 10 rats.

\section{Working groups}

Group $1(\mathrm{n}=10)$ : Colitis induced by TNBS, rats will face a 120-minute duration laparoscopic surgery (pneumoperitoneum group).

Group $2(n=10)$ : Colitis induced by TNBS, rats will face a 120-minute duration conventional surgery (open surgery group).

\section{Colitis model}

The subjects were given a light anaesthesia following 24 hours fasting. We used $5 \mathrm{Fr}$ polyurethane plastic cannula and introduced through the anus $8 \mathrm{~cm}$ further to give $5 \% 0.25 \mathrm{~mL} 10 \mathrm{mg} / \mathrm{kg}$ TNBS (Sigma, USA) in $50 \%$ ethanol to induce colitis. The rats were held upside down to prevent reflux of the solution from the anus.

\section{Surgery}

After the induction of colitis, the subjects were prepared for operation. The rats were randomly assigned to two groups for open and laparoscopic surgery.

All the rats were given general anaesthesia and spontaneous respiration was sustained by using $10 \mathrm{mg} / \mathrm{kg}$ ketamine hydrochloride (Ketalar ${ }^{\circledR}$, Eczacibasi) i.m. and $5 \mathrm{mg} / \mathrm{kg}$ Xylazin (Rompun ${ }^{\circledR}$, Bayer). Surgical sterilization was maintained during the operative period

Pneumoperitoneum was achieved in group 1 rats by introducing the veres needle through the mid-abdomen and maintaining an intraabdominal pressure of $8 \mathrm{mmHg}$ for 120 -minute duration by using an insufflator device. Group 2 rats were scrubbed with poviodineiodine solution following shaving the abdomen, a midline incision was performed for laparotomy. Sterile packs of gauze soaked with $0.9 \% \mathrm{NaCl}$ were draped over the organs in the abdominal cavity for 120 minutes.

All the subjects in both groups were sacrificed after 120-minute waiting period by giving high dose of Ketamine. Samples of blood for biochemical study were taken through cardiac puncture. Tissue samples from colon and pancreas were taken for biochemical (in dry tube) and histopathologic (in 10\% formaldehyde) examinations. Sterilization was kept strict throughout all the procedures.

\section{Biochemical assessment}

Blood and tissue (pancreas, colon) samples were taken. Blood samples were drawn by using sterile syringe through intra-cardiac puncture and collected in silicone sample tubes. After centrifugation, the serum was investigated for tumour necrosis factor alpha (TNF- $\alpha$ ), Interleukin 6 (IL-6), malonedialdehyde (MDA), nitric oxide (NO), and pancreatic specific protein (PAP I). Tissue samples were washed with $0.9 \% \mathrm{NaCl}$, weighed and homogenised by the method according to Sier et al. [4]. TNF- $\alpha$, IL-6, MDA, NO and myeloperoxidase (MPO) in colonic tissue; TNF- $\alpha$, IL-6, MDA, NO and PAP in pancreatic tissue were investigated in the biochemistry laboratory of Istanbul Cerrahpasa Medical School.

SerumTNF $(\mathrm{pg} / \mathrm{ml})$ and IL-6 $(\mathrm{pg} / \mathrm{ml})$ levels were measured by immuno-enzymatic ELISA method (Quantikine High Sensitivity Human by R\&D Systems, USA) by using the developer's protocol. Tissue MDA levels were measured by thiobarbituric acid reactant method and reported as $\mathrm{nmol} / \mathrm{L}$. Pancreatic specific protein was measured using ELISA method (PancrePAP, Dynabio) (\%). Tissue NO levels were calculated by Griess separator and reported as $\mathrm{mmol} / \mathrm{L}[6]$. With the use of Kruidener method, tissue MPO activity was measured and reported as $\mathrm{U} / \mathrm{mg}$ protein [7].

\section{Pathologic evaluation}

The severity of TNBS induced colitis was assessed by the loss of the body weight and the quality of feces. Histopathologic analyses were evaluated by an experienced pathologist blindly without knowing the sample was taken from which group. Colonic and pancreatic samples were fixed in $10 \%$ formaldehyde and a paraffin block follow-up was provided so that 4-5 micron sections could be obtained and stained with Hemotoxylene-Eosine dye.

Histopathologic scoring for pancreas: The scoring criteria for pancreatic tissues from both groups are given in Table 1. Scoring criteria was further adapted to the statistical method.

Histopathologic scoring for colon: To macroscopically and microscopically assess the colon mucosa, lesions in the mucosal surface were evaluated and scored for depth, width and distribution.

\section{Statistical assessment}

The statistical software SPSS 15.0 for windows was used analysis. Results were reported as mean \pm SEM. Comparisons between the groups were analyzed by Chi-Square and Fisher's exact tests. Biochemical data was evaluated by Mann-Whitney U test. $\mathrm{p} \leq 0.05$ value was accepted as statistically significant.

\section{Results}

\section{Biochemical evaluation results}

Serum biochemistry assessment results: TNF- $\alpha$, IL-6, MDA, NO and PAP levels in laparoscopic surgery group were significantly lower compared to open surgery group. The results and statistical analysis are provided in Table 2, Figures 1 and Figure 2.

\begin{tabular}{|l|l|l|l|l|}
\hline Score & Oedema & Inflammatory cells & Necrosis & Hemorrhagic spots \\
\hline $\mathbf{0}$ & - & - & - & None \\
\hline $\mathbf{1}$ & Mild & Mild & Mild & Present \\
\hline $\mathbf{2}$ & Intermediate & Intermediate & Intermediate & - \\
\hline $\mathbf{3}$ & Severe & Severe & Severe & - \\
\hline
\end{tabular}

Table 1: The histological criteria for the assessment of the pancratic tissue damage.

\begin{tabular}{|l|l|l|l|l|l|l|l|}
\hline & & TNF & IL6 & MDA & NO & PAP & MPO \\
\hline & Lap. & 0,45 & 0,45 & 1,61 & 147 & 69,7 & \\
\hline Blood & Conv. & 0,72 & 0,76 & 2,39 & 169,8 & 81,1 & \\
\hline & $P$ & $<0,000$ & $<0,000$ & $<0,000$ & $<0,000$ & $<0,000$ & \\
\hline & Lap. & 0,33 & 0,26 & 1,66 & 109,2 & 57,6 & \\
\hline Pancreas & Conv. & 0,5 & 0,46 & 3,1 & 157,2 & 84,5 & \\
\hline & $P$ & $<0,000$ & $<0,000$ & $<0,000$ & $<0,000$ & $<0,000$ & \\
\hline & Lap. & 0,45 & 0,41 & 2,36 & 191,2 & & 0,45 \\
\hline Colon & Conv. & 0,53 & 0,51 & 2,29 & 183,5 & & 0,47 \\
\hline & $P$ & $<0,000$ & $<0,000$ & 0,97 & 074 & & $<0,000$ \\
\hline
\end{tabular}

Table 2: Investigated parameters.

\begin{tabular}{|c|c|c|c|c|c|c|c|c|}
\hline & & & \multicolumn{5}{|c|}{ Colonic pathological assessment } & \\
\hline & \multicolumn{2}{|c|}{ Oedema } & \multicolumn{2}{|c|}{ Congestion } & \multicolumn{2}{|c|}{ Focal erosion } & \multicolumn{2}{|l|}{ Ulcer } \\
\hline & None & Present & None & Present & None & Present & None & Present \\
\hline Laparoscopic & 0 & 10 & 0 & 10 & 1 & 9 & 0 & 10 \\
\hline Conventional & 0 & 10 & 1 & 9 & 0 & 10 & 0 & 10 \\
\hline$p$ & & & .500 & & .500 & & & \\
\hline
\end{tabular}

Table 3: Histopathological examinatin results of the colon in laparoscopic and open surgery groups. (Statistically tested with chi-Square, $p \leq 0.05$ accepted as significant). 
Colonic tissue biochemical assessment results: The results were significantly different in groups 2 and 3 compared to group 1. In laparoscopic surgery group TNF- $\alpha$, IL-6 and MPO levels were significantly lower than open surgery group, while MDA and NO levels showed no statistical difference $(p=0.971, p=0.739)$. The results and statistical analysis are provided in Table 3, Figures 3 and Figure 4.

Pancreatic tissue biochemical assessment results: TNF- $\alpha$, IL-6, MDA, NO and PAP levels were significantly lower compared to open surgery group. The results and statistical analysis are provided in Table 1, Figures 5 and Figure 6.

\section{Histopathologic evaluation results}

Colonic tissue macroscopic assessment results: Hyperaemia, ulcerations and inflammation on the colonic mucosa were evaluated. Statistical analysis revealed that for the macroscopic colitis scoring evaluation there was no difference between both groups ( $p>0.05)$.

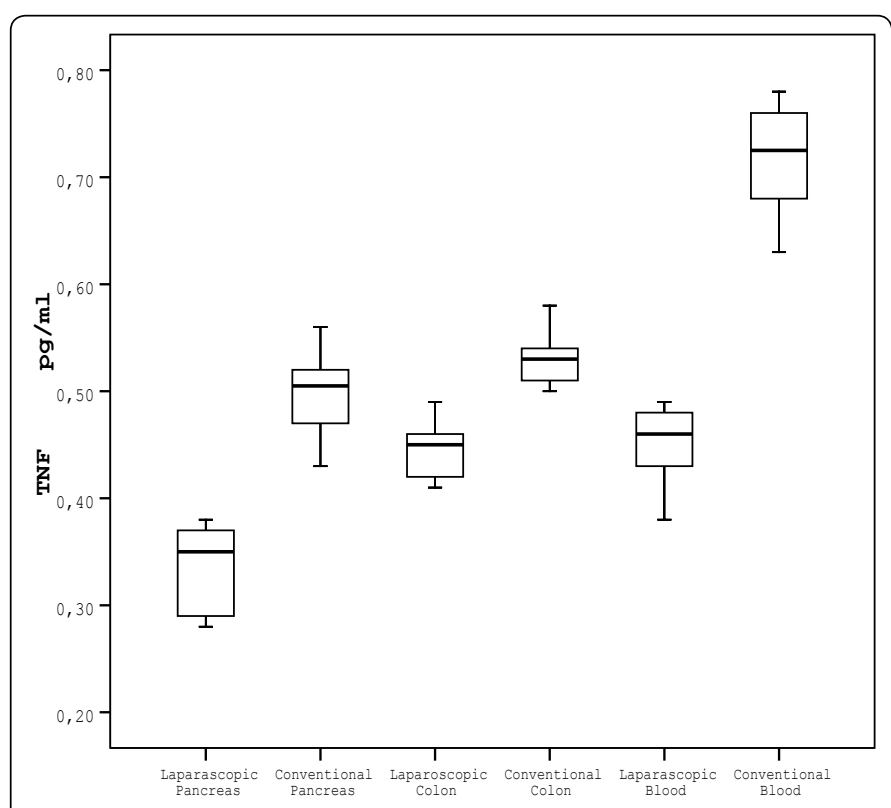

Figure 1: TNF levels ( Blood $p<0,000$, colon $p<0,000$, pancreas $p<0,000$ )

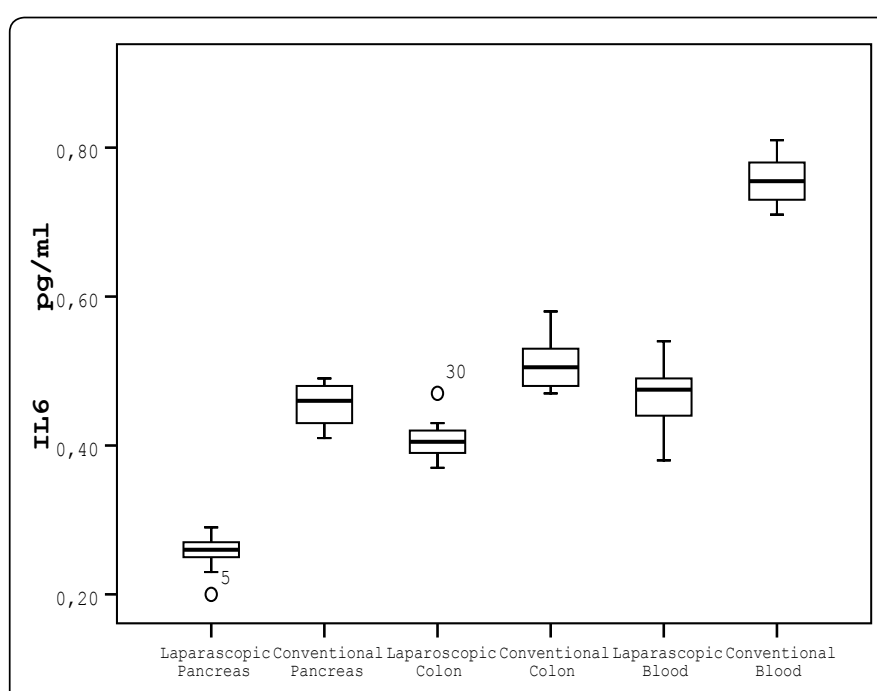

Figure 2: IL6 levels (Blood $p<0,000$, colon $p<0,000$, pancreas $p<0,000$ ).

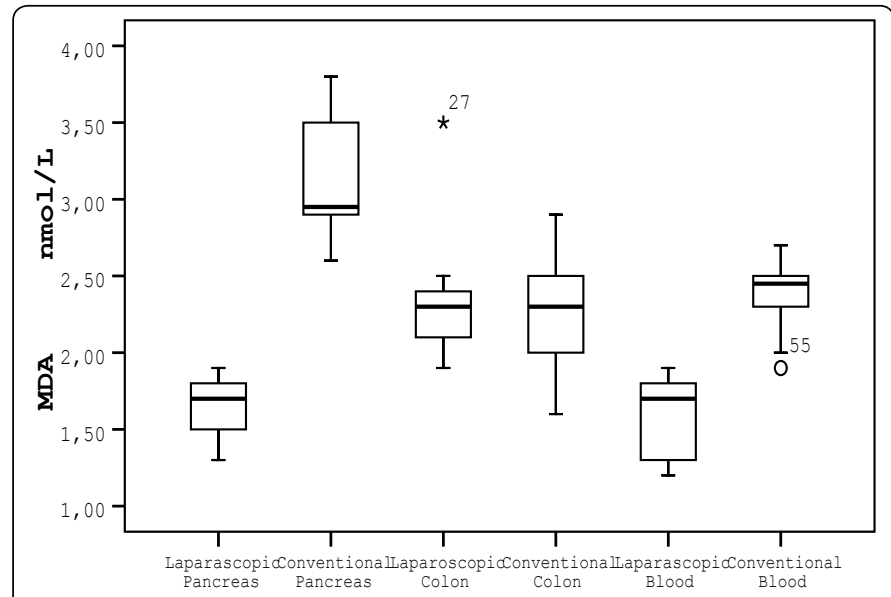

Figure 3: MDA levels (Blood $p<0,000$, colon $p=0,97$, pancreas $p<0,000$ )

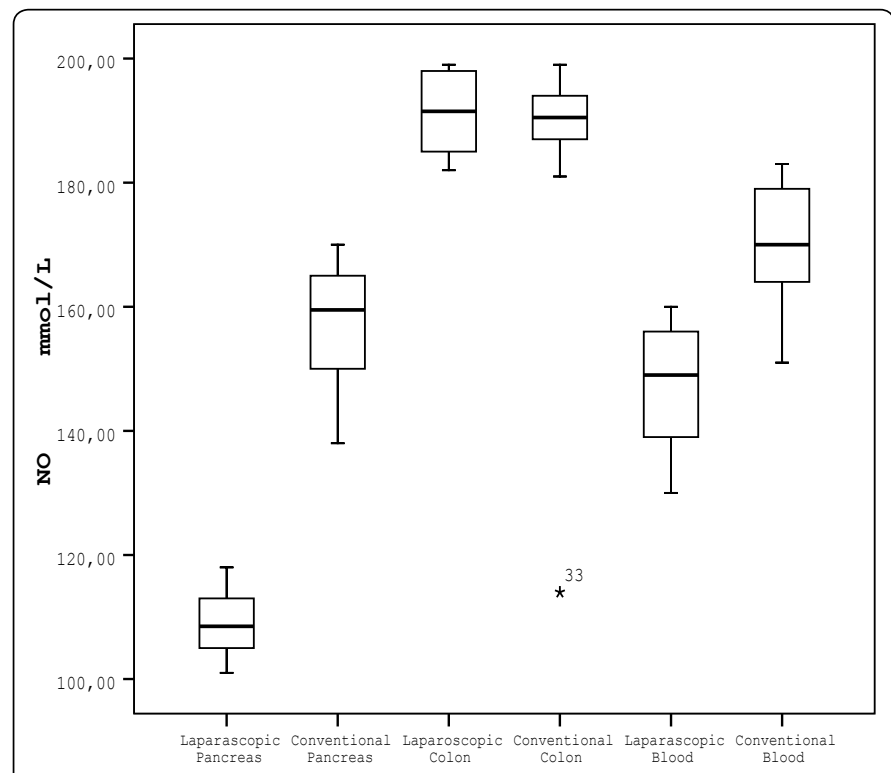

Figure 4: NO levels (Blood $p<0,000$, colon $p<0,74$, pancreas $p<0,000$ ).

Colonic tissue microscopic assessment results: Inflammation and oedema in mucosa, submucosa and muscularis mucosa, local erosions or deep ulcerations in submucosa through muscularis mucosa, deep ulcerations limited by coagulation necrosis reaching to the muscularis mucosa and characterized by with higher numbers of neutrophils than mononuclear cells were evaluated microscopically. But there was no difference between the laparoscopic and open surgery groups. The results are presented in Table 2, Figures 7 and Figure 8.

\section{Discussion}

IBD is a relapsing and remitting chronic disorder of young adults, and frequently seen in developed countries. Genetic predisposition, environmental factors, bacterial flora and immune system disorders are believed to play a role in its aetiology [1].

The response of the immune system within the gastrointestinal tract (GIT) becomes abnormal to several antigens and corresponding tissue damages are seen even in remote extra-intestinal organs in addition to the GIT. Huang et al. reported that pancreas and the biliary system disorders were frequent as remote organ problems in 
IBD with an incidence between 2.5 to $7.5 \%$ [8]. The reason is not fully understood. Another study demonstrated that the incidence of pancreatitis with UC was $1.2-1.5 \%$, but since it was usually clinically silent, it was frequently overlooked [9]. Similarly, autopsy series revealed a $14-53 \%$ either microscopic or macroscopic pancreatic lesions in cases of UC [10].

Although the rate of pancreatitis is undeniable in UC, it may be difficult to define the frequency of acute pancreatitis in the clinic. The drugs used in medical therapy (salycyclate, azothioprine etc.) of IBD are known to be a etiologic factor in the development of pancreatitis. It may be seen weeks after the commencement of the therapy, frequently run mild clinically, and often disappear after cessation of the treatment. In case acute pancreatitis developed, then the treatment may be continued with steroid, with a less risk for pancreatitis. But, still the risk of idiopathic pancreatitis is high $(1-1.5 \%)[2]$.

Both in UC and CD, the risk of pancreatitis is high. There are antipancreatic antibodies in the serum of the IBD patients, which are not present in other autoimmune or inflammatory disorders. Seibold et al. [11] reported that exocrine pancreas deficiency was present in $27 \%$ of antibody positive patients in contrast to $8 \%$ in patients without antibodies [11].

Studies demonstrated changes in the pancreatic canals that were determined by endoscopic retrograde pancreatography [12]. But even with these changes, the pancreatic function was found to be preserved. Although not fully known, the etiology of chronic pancreatitis in IBD is believed to be the exocrine damage associated with antipancreatic antibodies.

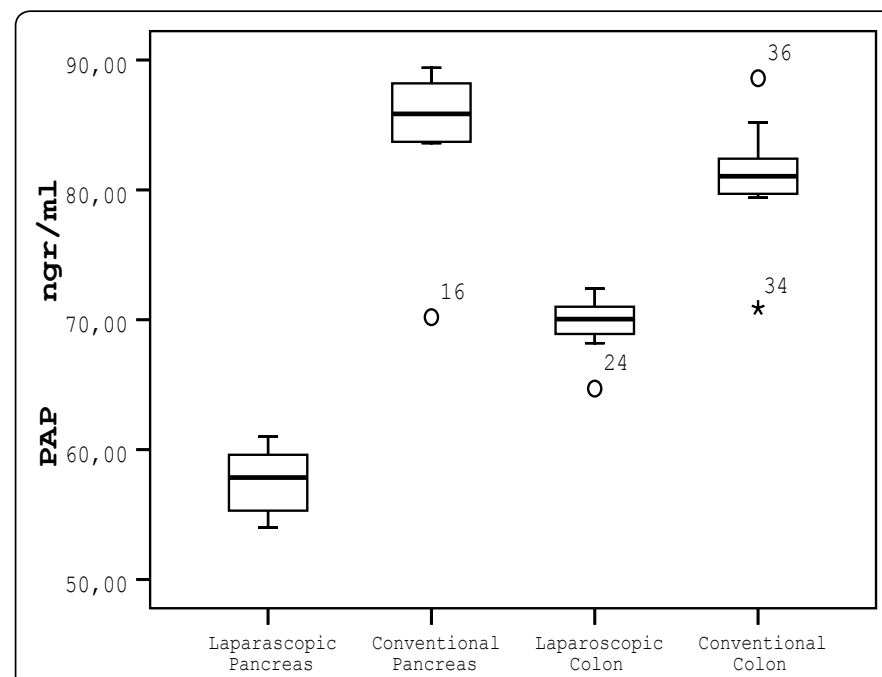

Figure 5: PAP levels (blood $p<0,000$, colon $p<0,000$, pancreas $p<0,000$ )

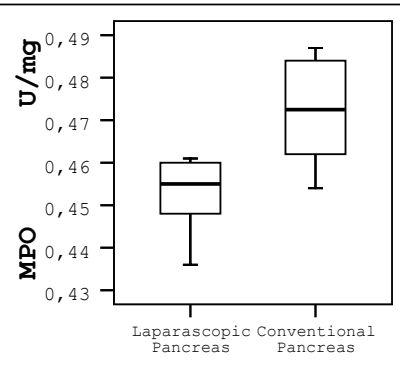

Figure 6: MPO levels in colonic tissue.

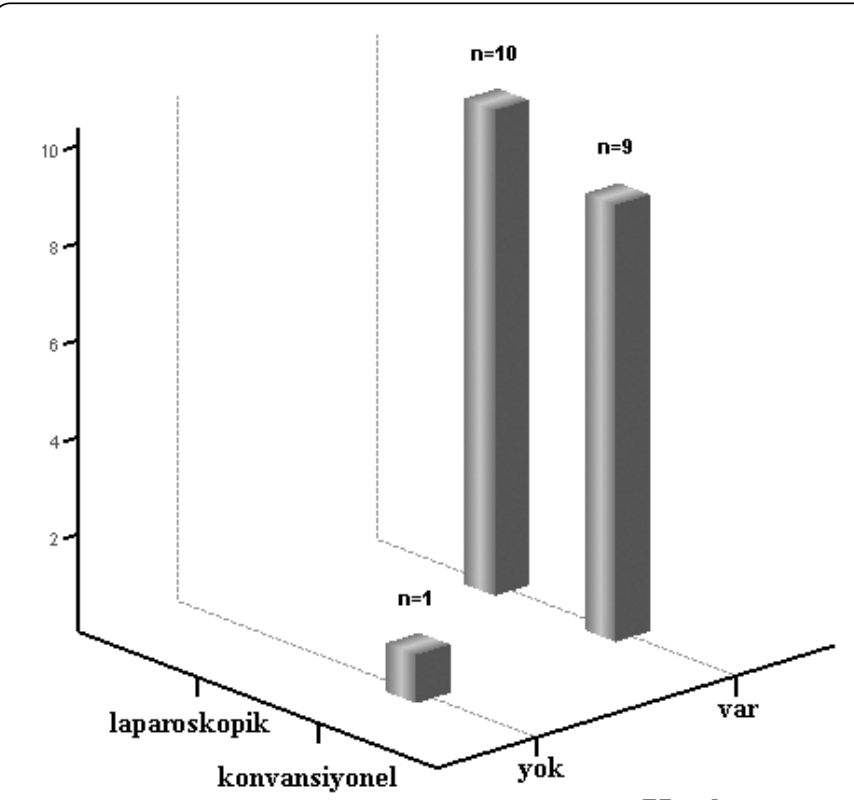

Konjesyon

Figure 7: Congestion in colonic tissue in both groups. No statistical difference was present.

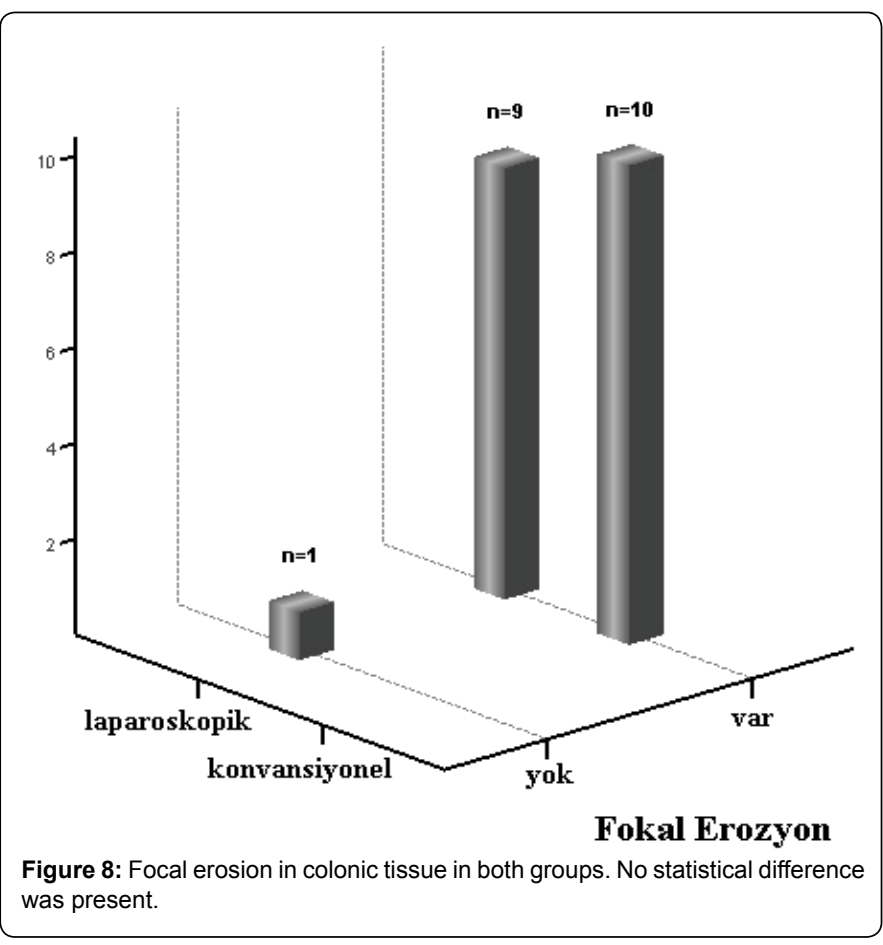

IBD is a systemic disorder; during its course pancreatitis may develop without apparent clinical reflection and cannot be detected with specific investigations. We studied the pancreatic specific protein for the detection of pancreatitis. Pancreatic specific protein (PAP I) is a secretory protein that is excreted from the pancreas during an acute attack $[13,14]$ and we found elevated pancreatic tissue and serum levels in both open and laparocopic surgery groups. It was appreciated as an indicator of pancreatitis without clinical signs.

Surgical therapy plays an important role when the UC, a systemic disorder, fails to respond medical treatment, when such complications 
as massive bledding, perforation or ileus develops and when there is a suspicion for malignancy.

Recently, laparoscopic surgery commenced to replace the standard conventional surgical treatments in most fields. It has the advantage of less incision with better postoperative pain and cosmetics, so that earlier return of gastrointestinal functions is possible and the patients starts earlier oral feeding $[15,16,17]$. It also makes an earlier return to work possible with less hospital stay and less hospital costs. It became possible to laparoscopically perform such operations with high morbidity rates as total proctcolectomy and ileal pouch-anal anastomosis, a golden standard in surgical treatment of UC $[3,18]$. As with the other laparoscopic procedures, the surgeon should also be experienced in the conventional open surgical operations for UC, though the complication rates are similar in both techniques; even tehere are less complications with laparoscopy [18].

In this study, we aimed to investigate the effects of different surgical techniques on colitis and on pancreatic tissue as well. In literature there are studies that frequently evaluated the consequences of UC on the hepatobiliary system and pancreas but there is no study thata compared the effects of laparoscopic and open surgery in case of IBD.

The effects of laparoscopy, especially due to the pneumoperitoneum, on the organ system were evaluated on since it was introduced to the the field in 1990s. Pneumoperitoneum is a generally required procedure so that the laparoscopic operation can easily be performed. Frequently $\mathrm{CO} 2$ insufflation is used for this purpose. Since the intraabdominal pressure increases, and also due to the presence of $\mathrm{CO} 2$ within the abdominal cavity, there are pathophysiologic effects on the intraabdominal organs; especially splanchnic organs are affected by hemodynamic changes. Pneumoperitoneum results in the reduction in the splanchnic circulation that results in production of free oxygen radicals and bacterial translocation [19]. Reperfusion injury following desufflation of the $\mathrm{CO} 2$ was demonstrated in the literature macroscopically [20].

A recent study demonstrated that pneumoperitoneum caused no effect on pancreas as with the open surgery but resulted a significant rise in serum ALT and AST levels in rats [21]. It also caused a reduction in portal blood circulation that let to hepatic dysfunction. Also, Akbulut et al. demonstrated a higher oxidative injury in rat kidneys following prolonged laparoscopy [22].

In our study, pneumoperitoneum resulted in no differences in microscopic examination of pancreatic tissue but there was a statistically significant decrease in the levels of PAP compared to open surgery group $(\mathrm{p} \leq 0.05)$. In regard to inflammatory and oxidative injury in pancreatic tissue, laparoscopy group showed a better outcome that was also statistically significant than open surgery group $(p \leq 0.05)$. Today laparoscopy projects further in the surgical field and has more supporters. The favourable outcomes on colonic and pancreatic tissue in our study make laparoscopy preferable in this area.

Trinitrobenzene sulphonic acid (TNBS) induced colitis model is a clinical process that results in oxidative injury in the colon and distant organs. Deger demonstrated that TNBS increased colonic oxidative injury which caused increased apopitosis in the colonic mucosal cells [10].

We investigated the effects of laparoscopy on the pancreatic and colonic oxidative injury in TNBS induced colitis rats. The levels of MDA and NO, the indicators of oxidative stress and lipid peroxidation, were evaluated and although we found no significant difference in oxidative injury for colonic tissue, laparoscopy produced a lesser injury on pancreatic tissue that was statistically significant $(\mathrm{P} \leq 0.05)$. Blood samples from both groups demonstrated a significant difference, and this was commented as the pneumoperitoneum in laparoscopic surgery resulted in less organ injury compared to open surgery group.

IL- 6 and TNF- $\alpha$ level in tissue and blood samples were significantly lower in the laparoscopy group $(\mathrm{P} \leq 0.05)$. Also the ratio of neutrophil sequestration that we used to evaluate the level of colitis and the levels of MPO which indicated tissue inflammation were significantly lower in the laparoscopy group $(\mathrm{P} \leq 0.05)$.

When the results of our study is evaluated it was cevident that the use of laparoscopic surgery in UC was safer than open surgery, but we could not find an answer that how the prolonged pneumoperitoneum had effects on abdominal organs. Pancreatic tissue showed a better tolerance to pneumoperitoneum and its oxidative injury resulted very limited effect on the general oxidative stress level of the body that also supports the view which accepts laparoscopy as a minimal invasive procedure. We found that oxidative injury parameters in pancreatic tissue and the course of pancreatitis were worse in the open surgery group.

The results let us to conclude that although the prolonged pneumoperitoneum may be expected to induce the oxidative injury in pancreas and worsen the course of pancreatitis, this injury level is less than the open surgery group and that laparoscopy is safer in IBD.

\section{Conclusion}

In our study we compared the laparoscopic and open surgical treatment of ulceratice colitis. Both procedures showed similar histopathologic effects and neither one overweighed. Additionally, pancreatic specific studies and other biochemical investigations favourably drew the attention that they demonstrated lesser inflammatory and oxidative insults in colonic and pancreatic tissues in case of laparoscopy compared to open surgery.

The view in the literature that suggests laparocopy is a minimal invasive surgical technique, a surgical procedure which results in lesser inflammation and oxidative injury, is also supported in our study. We found the similar systemic findings in colitis as in the literature.

The most important finding in this study is that even though it's pathophysiologic effects laparoscopic surgery was better than open conventional surgery in ulcerative colitis. We believe that to comment on the effects of prolonged pneumoperitoneum, there is a need for clinical and experimental studies of variable duration.

\section{References}

1. Kucharzik T, Maaser C, Lügering A, Kagnoff M, Mayer L, et al. (2006) Recent Understanding of IBD Pathogeneesis: Implications for Future Therapies. Inflamm Bowel Dis 12: 1068-1083.

2. Rothfuss KS, Stange EF, Herrlinger KR (2006) Extraintestinal manifestations and complications in inflammatory bowel diseases. World J Gastroenterol 12 4819-4831.

3. Hwang JM, Varma MG (2008) Surgery for inflammatory bowel disease. World Gastroenterol 14: 2678-2690.

4. Sier CF, Kubben FJ, Ganesh S, Heerding MM, Griffioen G, et al. (1996) Tissue levels of matrix metalloproteinases MMP-2 and MMP-9 are related to the overall Survival of patients with gastric Carcinoma. Br J Cancer 74: 413-417.

5. Carroccio A, lovanna JL, lacono G, Li Pani M, Montalto G, et al. (1997) 
Citation: Karatepe O, Kokdas S, Kamali S, Aydın T, KemikA, et al. (2010) The Comparison between Laparoscopic vs. Open Surgery for Trinitrobenzene Sulfonic Acid-Induced Rat Colitis. J Cytol Histol 1:109. doi:10.4172/2157-7099.1000109

Page 6 of 6

Pancreatitis associated protein in patients with celiac disease: serum levels and immunocytochemical localization in small intestine. Digestion 58: 98-103.

6. Moshage H, Kok B, Huizenga JR, Jansen PL (1995) Nitrite and Nitrate Determinations in Plasma. A Critical Evaluation. Clin Chem 41: 892-896.

7. Kruidenier L, Kuiper I, Van Duijn W, Mieremet-Ooms MA, van Hogezand RA, et al. (2003) Imbalanced Secondary Mucosal antioxidant Response in Inflamatory Bowel Disease. J Pathol 201: 17-27.

8. Huang C, Lichtenstein DR (2002) Pancreatic and biliary tract disorders in inflammatory bowel disease. Gastrointest Endoscopy Clin N Am 12: 535-559.

9. Barthet M, Dubucquoy L, Garcia S, Gasmi M, Desreumaux P, et al. (2003) Pancreatic chganges in TNBS-induced colitis in mice. Gastroenterol clin Biol 27: 895-900.

10. Değer C, Erbil Y, Giriş M, Yanik BT, Tunca F, et al. (2006) The effect of glutamine on pancreatic damage in TNBS-Induced colitis. Dig Dis Sci 51: 1841-1846.

11. Seibold F, Scheurlen M, Müller A, Jenss H, Weber P (1996) Impaired pancreatic function in patients with Crohn's disease with and without pancreatic autoantibodies. J Clin Gastroenterol 22: 202-206.

12. Heikius B, Niemelä S, Lehtola J, Karttunen T, Lähde S (1996) Pankreatic duct abnormalities and pancreatic function in patients with chronic inflammatory bowel disease. Scand J Gastroenterol 31: 517-523.

13. Bödeker H, Fiedler F, Keim V, Dagorn JC, lovanna JL (1998) PancreatitisAssociated protein is upregulated in mouse pancreas during acute pancreatitis. Digestion 59: 186-191.

14. Closa D, Motoo Y, lovanna JL (2007) Pancreatitis-associates protein: from a lectin to an anti-inflamatorry cytocine. World J Gastroenterol 13: 170-174.
15. Chen HH, Wexner SD, Weiss EG, Nogueras JJ, Alabaz O, et al. (1998) Laparoscopic colectomy for benign colorectal disease is associated with a significant reduction in disability as compared with laparotomy. Surg Endosc 12: $1397-1400$

16. Delaney CP, Kiran RP, Senagore AJ, Brady K, Fazio VW (2003) Case-matched comparasion of clinical and financial outcome after laparoscopic or open colorectal surgery. Ann Surg 238: 67-72.

17. Braga M, Vignali A, Gianotti L, Zuliani W, Radaelli G, et al. (2002) Laporoscopic versus open coloectal surgery: A randomized trial on short-term outcome. Ann Surg 236: 759-766.

18. Casillas S, Delaney CP (2005) Laparoscopic surgery for inflammatory bowe disease. Dig Surg 22: 135-142.

19. Eleftheriadis E, Kotzampassi K, Papanotas K, Heliadis N, Sarris K (1996) Gut ischemia, oxidative stres, and bacterial translocation in elevated abdominal pressure in rats. World J Surg 20: 11-16.

20. Yilmaz S, Koken T, Tokyol C, Kahraman A, Akbulut G, et al. (2003) Can preconditioning reduce laparoscopy-induced tissue injury? Surg Endosc 17: 819-824.

21. Yol S, Bostanci EB, Ozogul Y, Zengin NI, Ozel U, et al. (2004) Effect of carbon dioxide pneumoperitoneum on the severity of acute pancreatitis. Surg Endosc 18: $1747-1751$

22. Akbulut G, Polat C, Aktepe F, Yilmaz S, Kahraman A, et al. (2004) The oxidative effect of prolonged $\mathrm{CO} 2$ pneumoperitoneum on renal tissue of rats. Surg Endosc 18: 1384-1388. 